Review Article

\title{
Teratogens: a public health issue - a Brazilian overview
}

Thiago Mazzu-Nascimento ${ }^{1,2}$, Débora Gusmão Melo ${ }^{3}$, Giorgio Gianini Morbioli ${ }^{1,2,4}$, Emanuel Carrilho ${ }^{1,2}$, Fernanda Sales Luiz Vianna ${ }^{5,6}$, André Anjos da Silva ${ }^{5,7}$ and Lavinia Schuler-Faccini ${ }^{5,6}$

${ }^{1}$ Instituto de Química de São Carlos, Universidade de São Paulo, São Carlos, SP, Brazil.

${ }^{2}$ Instituto Nacional de Ciência e Tecnologia de Bioanalitica, Campinas, SP, Brazil.

${ }^{3}$ Departamento de Medicina, Centro de Ciências Biológicas e da Saúde, Universidade Federal de São

Carlos, São Carlos, SP, Brazil.

${ }^{4}$ School of Chemistry and Biochemistry, Georgia Institute of Technology, Atlanta, GA, USA.

${ }^{5}$ Sistema Nacional de Informação sobre Agentes Teratogênicos (SIAT), Hospital de Clínicas de Porto Alegre, Porto Alegre, RS, Brazil.

${ }^{6}$ Programa de Pós-Graduação em Genética e Biologia Molecular, Departamento de Genética, Instituto de Biociências, Universidade Federal do Rio Grande do Sul, Porto Alegre, RS, Brazil.

${ }^{7}$ UNIVATES University, Lajeado, RS, Brazil.

\begin{abstract}
Congenital anomalies are already the second cause of infant mortality in Brazil, as in many other middle-income countries in Latin America. Birth defects are a result of both genetic and environmental factors, but a multifactorial etiology has been more frequently observed. Here, we address the environmental causes of birth defects - or teratogens - as a public health issue and present their mechanisms of action, categories and their respective maternal-fetal deleterious effects. We also present a survey from 2008 to 2013 of Brazilian cases involving congenital anomalies (annual average of 20,205), fetal deaths (annual average of 1,530), infant hospitalizations (annual average of 82,452), number of deaths of hospitalized infants (annual average of 2,175), and the average cost of hospitalizations (annual cost of $\$ 7,758$ ). Moreover, we report on Brazilian cases of teratogenesis due to the recent Zika virus infection, and to the use of misoprostol, thalidomide, alcohol and illicit drugs. Special attention has been given to the Zika virus infection, now proven to be responsible for the microcephaly outbreak in Brazil, with 8,039 cases under investigation (from October 2015 to June 2016). From those cases, 1,616 were confirmed and 324 deaths occurred due to microcephaly complications or alterations on the central nervous system. Congenital anomalies impact life quality and raise costs in specialized care, justifying the classification of teratogens as a public health issue.
\end{abstract}

Keywords: Birth defects, teratogens, Zika virus, pregnancy, public health.

Received: July 01, 2016; Accepted: October 07, 2016.

\section{Background}

Congenital anomalies are among the major causes of infant death worldwide (Brazilian Ministry of Health, $\mathrm{MoH})($ Egbe et al., 2015). In the United States, as in other high-income countries, birth defects are the main cause of infant mortality, being responsible for 1 out of 5 infant deaths (Petrini et al., 2002). Within the main causes of infant deaths in the United States, congenital malformations, deformations and chromosomal abnormalities appear in first place, representing $20.3 \%$ of total infant deaths in 2013 (Xu et al., 2016). These are also the reasons for $12 \%$ of all

Send correspondence to Lavinia Schuler-Faccini. Departamento de Genética, Instituto de Biociências, Universidade Federal do Rio Grande do Sul, Caixa postal 15053, Campus Agronomia, 91501-970 Porto Alegre, RS, Brazil. E-mail: lavinia.faccini@ufrgs.br pediatric hospitalizations (Egbe et al., 2015). In Latin America, congenital anomalies are between the second and fifth cause of death in children under 1 year of age (Bronberg et al., 2014). In Brazil, since 2000, they are the second main cause of infant death (Passos-Bueno et al., 2014), and among the three leading causes of infant hospitalizations, responsible for $37 \%$ of pediatric hospital admissions. In addition, the hospital mortality rate in children with malformations accounted for $9.8 \%$ of total deaths, almost twice as in children without malformations (Horovitz et al., 2005).

Congenital anomalies affect about 1 in 33 liveborns, with an estimated 3.2 million newborns with birth defects per year. Moreover, in 2013 a worldwide estimate showed that nearly 276,000 newborns die before one month of life every year, as a result of these congenital anomalies (World Health Organization, 2015a). From those, 10 to 25\% pres- 
ent specific genetic inheritance, $10 \%$ are caused by environmental factors, such as teratogens exposure, and 65 to $75 \%$ remain with unknown causes, what may include polygenic diseases, multifactorial factors (gene-environment interactions), spontaneous development abnormalities and synergistic interactions with teratogens (Brent, 2001).

Teratogens are environmental agents such as drugs, viruses, lack of nutrients, and physical or chemical elements that upon contact with embryo/fetus can cause congenital anomalies, generating permanent functional or morphological changes in the newborn (Shepard, 1982).

Among the main reasons for pregnant women having contact with teratogenic substances is the association of preexisting public health problems (such as lack of medical care, drug and alcohol consumption, lack of basic sanitation) to other social issues like poverty and illiteracy (Reidpath and Allotey, 2003; World Health Organization, 2015a). Therefore, the offspring of socially disadvantaged women are more vulnerable to birth defects, causing an impact on infant mortality and health expenses with specialized care, qualifying teratogens as a public health problem.

\section{Teratogenic agents}

Ancient Egypt wall paintings suggest the long time existence of congenital abnormalities, such as clubfoot and achondroplasia (Barrow, 1971). Children with congenital malformations were labeled as "monsters" by the ancients (Garcias and Schüler-Faccini, 2004). Other regions, such as the Americas, Australia and Pacific Islands also have early records of primitive sculptures revealing concerns with congenital anomalies, which have even inspired some mythological figures (Barrow, 1971). Only in the 1930s malformations started to be scientifically studied in animal models. Pioneer studies were performed in pig offspring, addressing dietary vitamin A deficiency in pregnant sows, which caused a complete absence of eye globe and ocular tissue in the newborns (Hale, 1933).

Between the 1950s and 1960s thalidomide was extensively used as sedative and to treat morning nausea during pregnancy in Europe, Australia, Canada, Japan and Brazil. Thalidomide use during pregnancy caused limb reduction defects in thousands of newborns, leading to its ban in most countries since 1961 (Kim and Scialli, 2011). The thalidomide tragedy caused an increasing interest about drug exposure during pregnancy and the mechanism of action of teratogenic agents on embryo-fetal abnormality development.

Humans are exposed to millions of potential deleterious substances and hazardous conditions daily. However, only a small part of these substances have been tested in animals and even fewer were confirmed as a teratogenic for humans, as teratogenicity studies cannot be conducted in humans due to ethical reasons (Kalter, 2003).

\section{Principles of Teratology}

Teratology studies establish relationships between environmental agents and anatomical and physiological changes in the fetus (Finnell, 1999; Kalter, 2003). We present below the six basic principles that determine teratogenic effects (Wilson, 1977; Finnell, 1999).

\section{Maternal-fetal genotype}

A teratogenic effect depends on maternal-fetal genotype and on how embryos interact with their surroundings. Due to these conditions, newborns exposed to a specific dose of the same teratogenic can show different phenotypes. Teratogens are capable of interacting with some genes, modifying morpho-functional patterns and resulting in either a major susceptibility or resistance to harmful substances. Some biochemical pathways can also respond in distinct ways to different agents, affecting even more malformation patterns (Cassina et al., 2012).

\section{Mechanisms of action}

The most common mechanisms of action of teratogens are hyperacetylation, cholesterol imbalance, alteration of folate metabolism and folate antagonism, retinoic acid imbalance, endocrine disruption, vascular disruption and oxidative stress (Giavini and Menegola, 2012).

\section{Hyperacetylation}

Hyperacetylation may occur due to the inhibition of histone deacetylase enzyme (HDAC), and the acetylation status of the histone affects the modulation of chromatin structure and gene expression, interfering with the embryonic development. HDAC inhibitors have been used as anticonvulsant drugs (valproic acid) and for cancer treatment, once they prevent tumorigenesis. Among anticancerdrugs are trichostatin A (TSA), apicidin and sodium butyrate. These drugs are able to induce hyperacetylation in animal embryos, leading to congenital malformations, such as neural tube and axial skeletal defects (Menegola et al., 2005).

\section{Cholesterol imbalance}

A high amount of cholesterol is required for fetal development. This biomolecule is supplied by the mother during early pregnancy and transported to the fetus across the placenta, while during late pregnancy, cholesterol biosynthesis will depend on the fetus' own production (Waterham, 2006). Drugs used for the treatment of hypercholesterolemia, such as statins, act by blocking HMG$\mathrm{CoA}$ reductase, the enzyme involved with cholesterol biosynthesis. HMG-CoA reductase is converted to mevalonate (Charlton-Menys and Durrington, 2008), interrupting the synthesis of cholesterol, and thus can cause adverse effects on the developing fetus (Edison and Muenke 2004). 


\section{Alteration in folate metabolism and folate antagonism}

Folate or water-soluble vitamin B acts as a co-enzyme in biochemical reactions, as a receiver or donor of onecarbon units, and it is involved in purine and pyrimidine synthesis and in DNA methylation. Increased cell growth and tissue proliferation during embryogenesis demands an increase in DNA synthesis, for which the presence of folate is essential. Some drugs can compete with dihydrofolate reductase and block the conversion of folate to tetrahydrofolate. Among these drugs are methotrexate, sulfasalazine, triamterene and trimethoprim. Other drugs, such as anti-epileptic drugs, can interfere in folate absorption or influence folate degradation (including valproic acid and carbamazepine phenytoin). The most common birth defects involving these drugs are neural tube defects, orofacial clefts and limb defects (van Gelder et al., 2010).

\section{Retinoic acid imbalance}

An imbalance between synthesis and degradation of retinoic acid can lead to an excess or deficiency of this acid, resulting in deleterious effects on cells and embryos, once this Vitamin A precursor is closely related to vertebrate morphogenesis. However, retinoic acid is also a signaling molecule in neural crest cells, which will originate various cell types and structures, such as intramembranous bone, cartilage, peripheral nerves and Schwann cells, and muscles, amongst others. Drugs such as isotretinoin can contribute to retinoic acid imbalance and lead to craniofacial and axial skeleton malformations (Giavini and Menegola, 2012).

\section{Endocrine disruptors}

Endocrine disruptors may interfere with the release of hormones and in reactions mediated by hormone receptors (van Gelder et al., 2010). Diethylstilbestrol, oral contraceptives, fertility treatment drugs and other endocrine disruptive chemicals, which can include bisphenol $\mathrm{A}$ and phthalates, act as endocrine disruptors (van Gelder et al., 2010). These teratogenic substances can cross the placenta and lead to fetal genital malformations (Raman-Wilms et al., 1995)

\section{Vascular disruption}

Changes in the development of veins, arteries and capillaries will disturb blood perfusion in fetal tissues. These maternal-fetal blood disturbances can include hyperperfusion, hypoperfusion, hypoxia and obstruction, and are caused by anatomical problems, maternal chronic diseases or exposure to teratogenic agents during pregnancy, such as misoprostol, phenytoin, cocaine, ergotamine, and some vasodilator and vasoconstrictor drugs. Structural birth defects are the most commonly reported, particularly limb defects (Holmes, 2002).

\section{Oxidative stress}

Oxidative damage to cellular macromolecules such as lipids, proteins, DNA and RNA is caused by reactive oxygen species (ROS), which provide oxidation-reduction reactions (Wells et al., 1997). Exogenous ROS sources include ultraviolet light (UV), UVA and UVB radiation, ionizing radiation, and chemical agents, while endogenous sources are related to cellular metabolism or oxidase enzymes (Hansen, 2006; van Gelder et al., 2010; Giavini and Menegola 2012). Some of these agents (also called proteratogens) can be bioactivated by embryonic cytochrome P450 enzymes. Their teratogenic effect will depend on the intracellular balance between proteratogen bioactivation, molecular target damage, maternal proteratogen elimination, and repair of damaged cells (Winn and Wells, 1995; Wells et al., 1997), as illustrated in Figure 1. Among drugs that induce oxidative stress are thalidomide, valproic acid, phenytoin, alcohol, (van Gelder et al., 2010), and anticancer drugs (Conklin 2004).

\section{Conceptus development stage}

Organisms present distinct sensitivity to external agents according to their gestational age. A conceptus is a fertilized egg cell until the $3^{\text {rd }}$ week of gestation. The period from the $3^{\text {rd }}$ to the $8^{\text {th }}$ week it is called embryonic phase, and from the $9^{\text {th }}$ week onward the fetal phase (Niakan et al., 2012). The critical phases of gestation are represented in Figure 2.

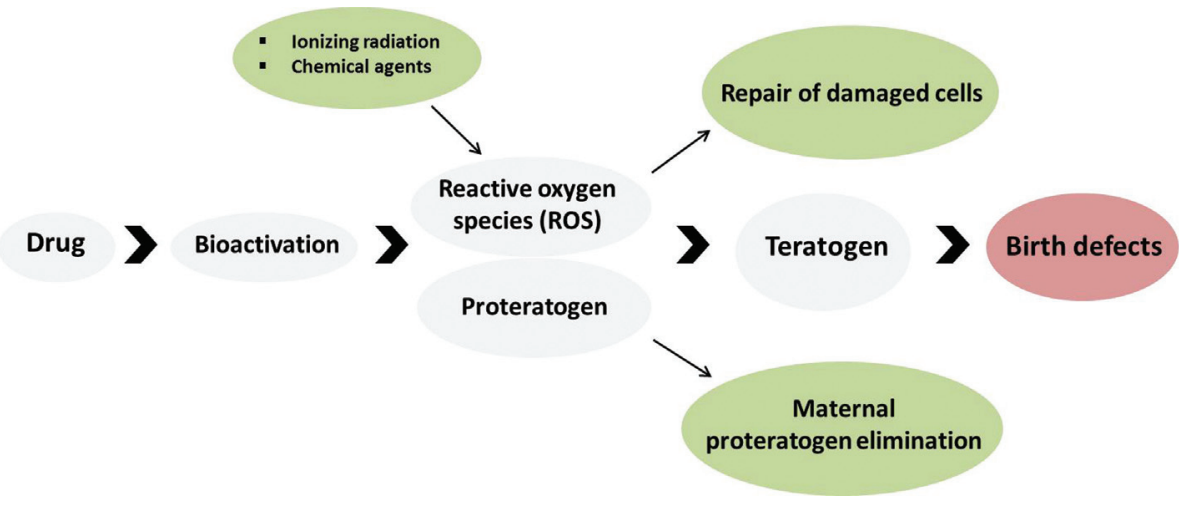

Figure 1 - Teratogenesis pathways due to oxidative stress. 


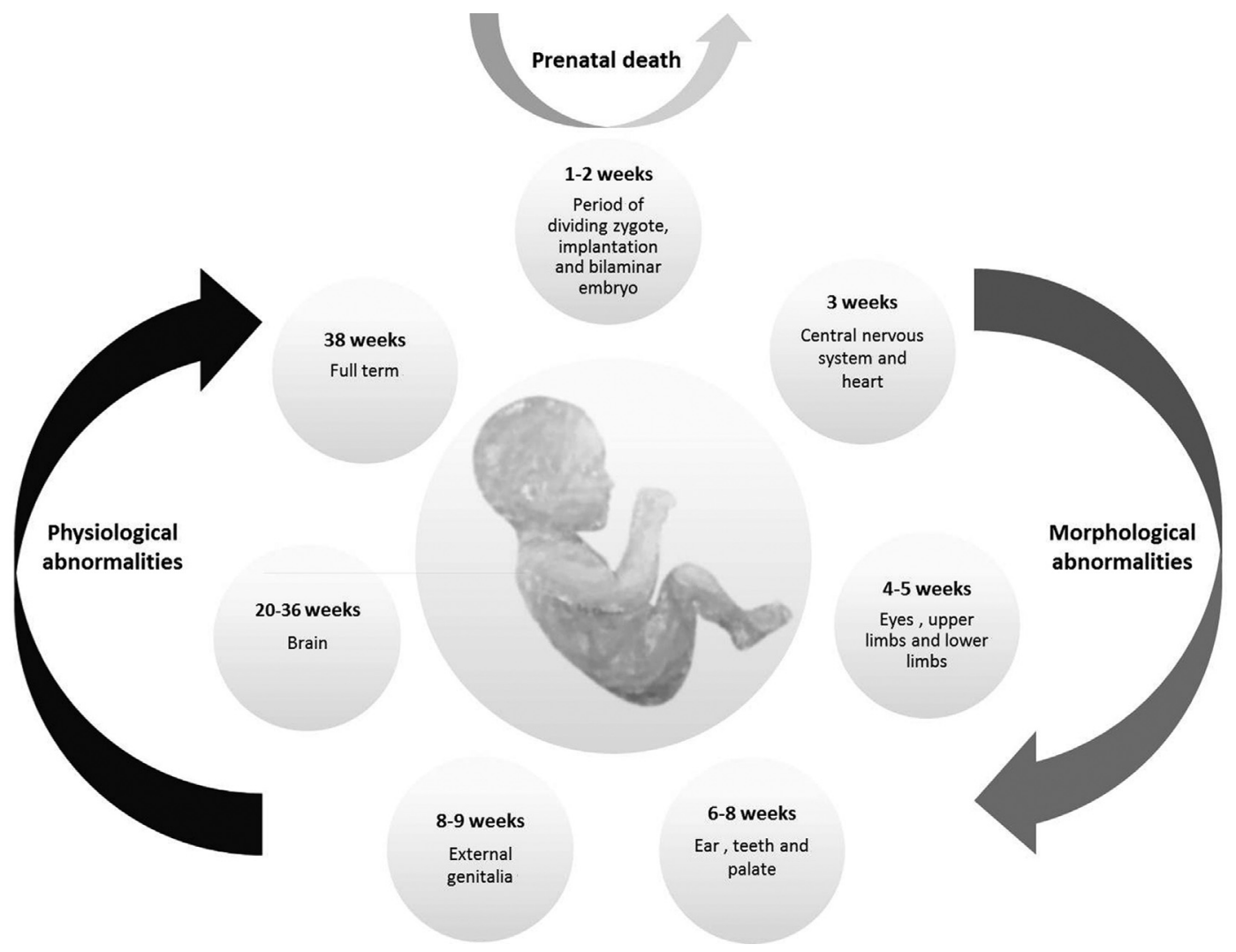

Figure 2 - Critical stages of human embryological development.

The two initial weeks after fertilization, in which the zygote is undergoing mitotic cell division is called the 'all-or-nothing' phase; in case a contact with a teratogenic agent occurs, it can result either in spontaneous abortion or in a normal embryo-fetal development. If teratogenic exposure occurs between the $3^{\text {rd }}$ and $8^{\text {th }}$ week of gestation, a period in which most of the morphological structures develop, it can lead to considerable phenotypical changes in the embryo, such as alterations in the central nervous system, limbs and face. From the $9^{\text {th }}$ week of gestation some organs are still developing, like external genitalia and brain, and exposure to teratogens can culminate in functional abnormalities. However most morphological characteristics are preserved from this phase onward (Shepard ,1979; Niakan et al., 2012).

\section{Nature of the agent}

Teratogenic agents can affect the embryo in different ways, according to the teratogen's nature. Physical teratogenic agents, such as ionizing radiation, affect the embryo directly. Drugs and other chemical substances on the other hand are previously metabolized by the mother's organism before reaching the fetus. This metabolism can either activate or inactivate relevant metabolites, resulting in different teratogenic susceptibilities (Finnell, 1999; GilbertBarness, 2010; Niakan et al., 2012).

\section{Dose-response relationship}

Considering basic principles of dose-response, prolonged teratogen exposure leads to worsened embryo-fetal sequelae. Dose is also a major factor, with evidence of short exposures to high teratogen doses leading to more deleterious effects (Cohlan, 1963; van Gelder et al., 2010).

\section{Final manifestation}

The resulting teratogenic effects are spontaneous abortion, fetal loss, embryo-fetal morphological abnormalities, intrauterine growth restriction, and functional disabilities, such as intellectual disability (Finnell, 1999; GilbertBarness, 2010).

Teratologists use Shepard's seven criteria to establish human teratogenicity (Shepard, 1994): 1) proven exposure to the agent during the critical stages of prenatal development; 2) consistent findings on two or more high-quality epidemiological studies (control of confounding factors, sufficient number of cases, exclusion of positive and negative bias, prospective studies, if possible); 3) careful delineation of clinical cases; 4) rare environmental exposure that is associated with the rare defect (three or more cases, at least); 5) teratogenicity in experimental animals; 6) the association should make biological sense; and 7) experimental proof that the agent acts in an unaltered state. Criteria 1-4 are considered essential. criteria 5, 6, and 7 are helpful but not essential. 


\section{Teratogen categories}

Teratogenic agents can be categorized into: I) drugs and substances, II) physical agents, III) environmental agents, IV) maternal infections, and V) maternal conditions (Gilbert-Barness, 2010). Table S1 (supplementary material) presents 44 teratogenic agents and their characteristics, as well as their respective birth defects.

\section{Teratogenic risks}

Due to concerns about teratogenic risks regarding medicinal drugs, the Food and Drug Administration (FDA) created a risk classification for these substances during an international symposium of the Teratology Society in 1992 (Alván et al., 1995). Substances are classified following a progressive risk order (A, B, C, D and X) (Food and Drug Administration, 2014a; Alván et al., 1995): A) controlled studies did not show risk to the fetus; B) absence of risk to humans or results from tests on animals did not show fetal risk; C) risks cannot be rejected; controlled studies in humans are scarce or inexistent; although animals studies had positive results, there is no human data available; there may be adverse effects on the fetus (drug benefits must justify fetal risk; D) studies have shown risk to the fetus (substance prescription depends on the mother's need, to preserve the mother's life); X) contraindicated in pregnancy; risk to the fetus is greater than the benefit of the drug.

However, as this classification allowed for misinterpretation and errors in prescribing decisions, the FDA removed pregnancy letter categories (A, B, C, D, and X), and published a new final rule, the "Pregnancy and Lactation Labeling Rule" (PLLR), for classification based on a narrative structure rather than a category system, which provides a clearer description of potential risks of drug exposure during pregnancy. From June 30, 2015, these labeling changes came into effect, to which prescription of drugs and biological products have to comply. This final rule requires the use of the following subsections: I) Pregnancy - information about use of the drug in pregnant women, which includes the dosing and potential risks to the developing fetus; information about registries of pregnant women affected by a drug or biological product, and a recommendation of inclusion in the drug label of the existence of any pregnancy registries; II) Lactation - information about using the drug while breastfeeding, which includes the amount of drug in breast milk and possible effects on the breastfed child; III) Reproductive Potential of Females and Males - information about the need for pregnancy testing, contraception recommendations, and infertility related to the drug (Food and Drug Administration, 2014b).

\section{Why are teratogens a public health problem?}

Preexisting public health problems, such as alcohol and drug consumption, malnutrition of pregnant woman (Scholl and Johnson, 2000), precarious health conditions, lack of infrastructure and information (McMichael et al., 2005) contribute to the contact of pregnant women with teratogenic agents and may interact as risk factors for fetal outcome. Other factors, such as illiteracy, familiar issues and low income aggravate the situation (Nutbeam, 2006), impacting infant mortality and costs on specialized medical treatment, and aggravating other public health issues.

\section{Survey of birth defects cases in Brazil}

The survey data are from the online platform of the Brazilian Ministry of Health (MoH) based on records of the Unified Health System (SUS). DATASUS (http://www2.datasus.gov.br/DATASUS/index.php?area $=02$ ) is a computerized system that provides a database with information about birth statistics (mortality and live births), epidemiology and morbidity, health indicators, and demographic and socioeconomic information.

The SINASC (Information System of Live Births) and SIM (Mortality Information System) databases, which have information about the number of cases of children born with birth defects (Figure 3A) and the number of fetal deaths (Figure 3B) from 2008 to 2013, registered 121,233 infants with congenital anomalies, an annual average of 20,205 cases (Figure 3A). If we consider that the Brazilian annual birth rate average of this period is about 2,900,000 (SINASC), there is a $0.7 \%$ prevalence of births with anomalies. Although this may seem a small number, it is worth noting that the $\sim 20,000$ infants born with anomalies every year directly impact the public health system. However, studies have shown that there is a clear underreporting, as the rate for birth defects in humans is around 3\% (Parker et al., 2010; Xu et al., 2016). Depending on the disability, these children will require specific treatments, ranging from educational specialists, to physical therapy, or surgical interventions. Moreover, in addition to these birth defects there were 9,178 fetal deaths due to congenital anomalies reported during the same period, corresponding to an annual average of 1,530 (Figure 3B).

Another survey was performed in the SIH/SUS (Hospital Information System/ Unified Health System) databases, using as a parameter the hospital morbidity lists by ICD-10 (International Classification of Diseases) from 2008 to 2013. The following variables were searched: infant hospitalizations involving birth defects per year (Figure 3C), deaths of hospitalized patients due to birth defects (Figure 3D), and average cost of hospitalizations due to birth defects (Figure 3E). Figure 3C shows that during this period there were a total of 494,714 infant hospitalizations due to birth defects, which represents an annual average of 82,452 .

There were 13,050 reported deaths (Figure 3D), with an average of 2,175 per year. Thus, the number of children dying after hospitalization is higher than the number of fetal deaths due to congenital anomalies. About $3 \%$ of children who were hospitalized with birth defects died, which, 
(A)

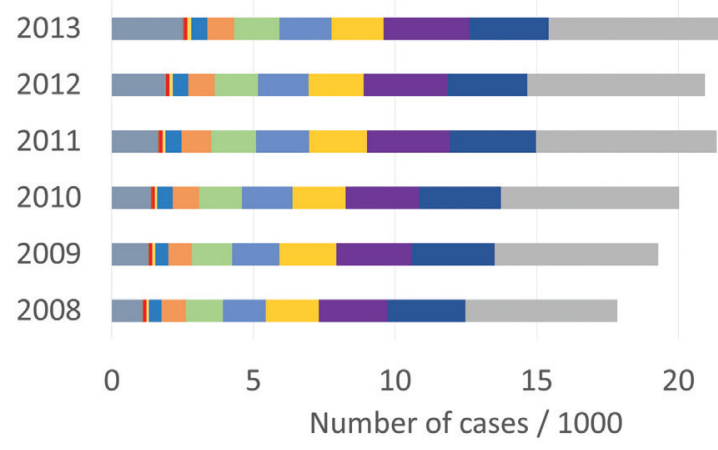

(C)

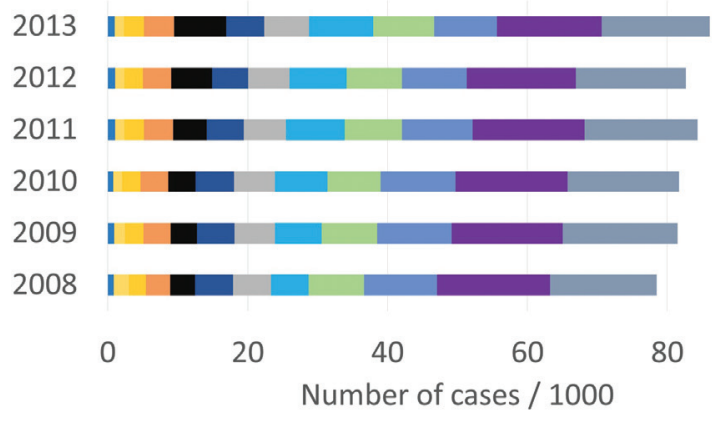

(E)

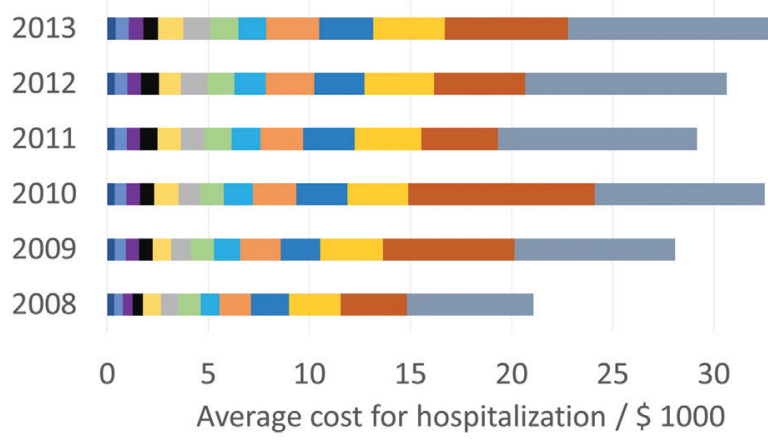

Sources: Ministério da Saúde - Sistema de Informações Hospitalares do SUS (SIH/SUS). MS/SVS/DASIS - Sistema de Informações sobre Nascidos Vivos - SINASC. MS/SVS/CGIAE - Sistema de Informações sobre Mortalidade - SIM.

*Currency rate: $\$ 1.00=\mathrm{R} \$ 3.75$
(B)

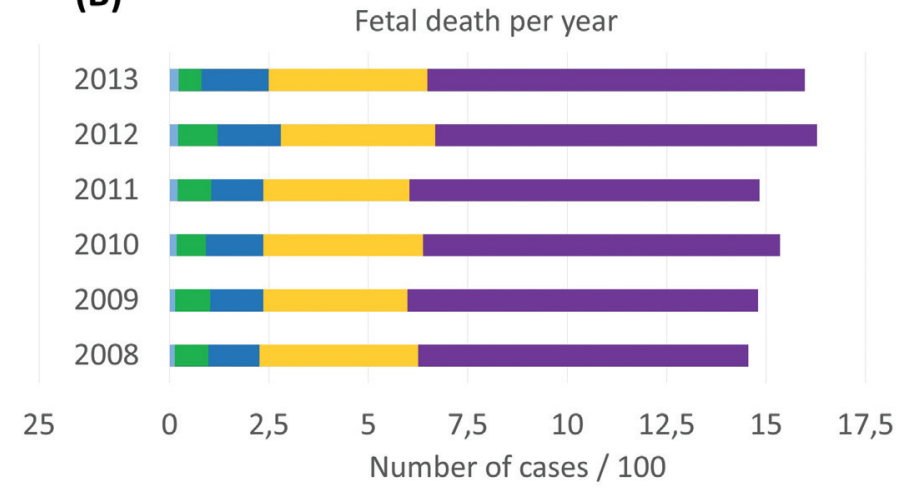

(D)

Death during hospitalization per year

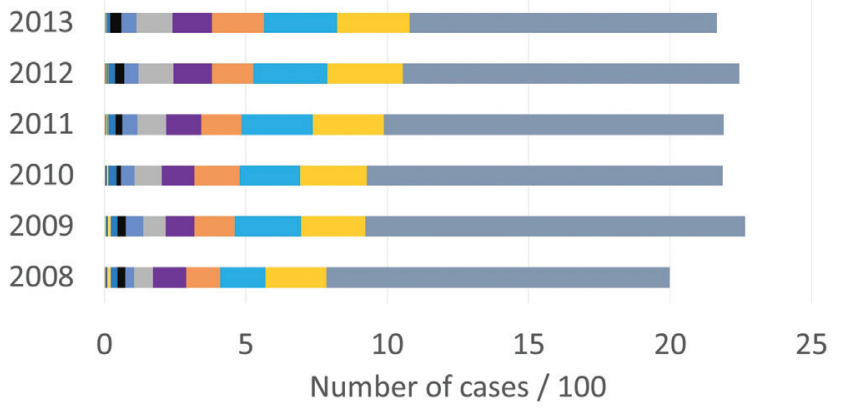

Cleft Lip and Cleft Palate

- Congenital Abnormalities of the feet

Congenital Abnormalities of the Hip

- Congenital absence, atresia, and stenosis of small intestine

- Congenital malformations of heart

Congenital malformations of the circulatory system

- Congenital syphilis

- Dentofacial anomalies

- Hemangioma and lymphangioma

- Hydrocephalus and spina bifida Congenital

- Infectious and parasitic diseases congenital

- Other congenital malformations

- Other congenital malformations of the circulatory system

- Other congenital malformations of the digestive system

- Other congenital malformations of the musculoskeletal system

- Other congenital malformations of the nervous system

- Other malformations of the genitourinary system

- Other specific tegumental affections in newborns

- Spina bifida

Figure 3 - Comprehensive survey of birth defects in Brazil from 2008 to 2013. A) Number of children born with birth defects. B) Number of fetal deaths. C) Number of hospitalizations involving birth defects per year. D) Number of deaths of hospitalized patients due to birth defects. E) Costs associated with treatment and on hospitalization's admissions.

added to the 1,530 fetal deaths, totals 3,705 annual deaths. The total cost associated with infant hospitalization involving congenital anomalies was 46,550 USD during these six years (Figure $3 \mathrm{E}$ ), corresponding to an annual average of 7,758 USD.

Furthermore, in addition to hospital costs, patients with chronic conditions will need continuous treatment, in- creasing even more the associated costs. These costs can include drugs, physiotherapy, speech therapy, occupational therapy and special education, and in many instances the mother quits her job to care for the child (Horovitz et al., 2005).

Tables S2-S6 are attached as supplementary material and contain the raw data (2008 to 2013) from the Brazilian 
Ministry of Health website. As can be seen, there is a lack of specification in the records jeopardizing the identification of the etiology of the possible teratogens. Better epidemiological information would be very important for the detection of new teratogens, as well as for their proper control. The microcephaly epidemics, as we will show below, is an example of how the lack of proper registries in many countries made it difficult to identify the real impact of the Zika virus infection in pregnancy and the extent of the resulting birth defects.

\section{Brazilian cases of teratogenesis}

\section{Microcephaly outbreak in Brazil and Zika prenatal virus infection}

In 2015 there was a sudden appearance of Zika virus (ZIKV) infections in Brazil, especially in the Northeast region (Campos et al., 2015). Climatic factors, lack of infrastructure, and the population's negligence offered favorable conditions for the proliferation of Aedes sp. mosquitoes, the Zika virus vector (Costa et al., 2008). Furthermore, recent studies suggest a potential sexual transmission of Zika virus (Musso et al., 2015; Atkinson et al., 2016; D'Ortenzio et al., 2016), increasing the concern received from public authorities. The principal reason for alarm is the increased risk of the unborn babies to develop neurological and brain abnormalities, characterized by microcephaly, when infected by Zika virus during pregnancy (Mlakar et al., 2016; Rasmussen et al., 2016).

From 2010 to 2014 there was an average of 160 cases of microcephaly per year in Brazil (Brazil Ministry of Health, 2015). A drastic increase was reported from October 22, 2015 to June 18, 2016, with 8,039 suspected and 1,616 confirmed cases of microcephaly (Brazil Ministry of Health, 2016). The cases occurred in 576 municipalities, throughout all 26 Brazilian States and the Federal District. In a study analyzing the first 1,501 cases of microcephaly reported to the Brazilian $\mathrm{MoH}, 602$ were included as possibly related to ZIKV prenatal infection (depending on the level of laboratorial, radiological or clinical evidence) (França et al., 2016).

Microcephaly can be caused by genetic, environmental or multifactorial causes (Alcantara and O'Driscoll, 2014). The astonishing increase in the reported number of cases of microcephaly in 2015 led the Brazilian $\mathrm{MoH}$ to declare state of emergency in the country (Brazil MoH, 2015), and on February, 2016, the World Health Organization (WHO), in turn, declared the large number of cases of microcephaly and neurological disorders and their possible relationship with ZIKV a Public Health Emergency of International Concern (PHEIC) (World Health Organization, 2016).

Soon after, the ZIKV genome was detected in the amniotic fluid of pregnant women whose fetuses presented microcephaly (Calvet et al., 2016), as well as in the brain of aborted fetuses, in urine, and in cerebrospinal fluid (Brasil et al., 2016; Mlakar et al., 2016).

Rasmussen et al. (2016), using Shepard's criteria for defining a human teratogen, concluded that there was enough evidence to establish the causal relationship between ZIKV infection during pregnancy and microcephaly, in addition to other brain anomalies. Studies in mice revealed that the Brazilian Zika virus (ZIKVBR) is capable of infecting the fetus, leading to intrauterine growth restriction, including microcephaly (Cugola et al., 2016). Other studies showed that ZIKV targets human brain cells (Garcez et al., 2016), clearly revealing the association between ZIKV infection during the first trimester of pregnancy and microcephaly risk (Johansson et al., 2016).

Microcephaly can lead to several complications, such as intellectual disability, growth retardation, strabism, epilepsy, metabolic disorders, and cerebral palsy (Watemberg et al., 2002; Ashwal et al., 2009), with an enormous economic and social impact for the country in future years. Therefore, effective actions should be implemented immediately to contain the ZIKV spread. Those actions should include better access to public sanitation and health policies, control of the Aedes vector, which also transmits other tropical diseases such as dengue and yellow fever, along with the search for effective vaccination and pharmacological treatment.

\section{Misoprostol}

In developing countries there is an early sexual initiation and lack of family planning. Women tend to be aware of pregnancy weeks or even months later (De Moura and Gomes, 2014), and there is a high rate of undesired pregnancies.

In countries were abortion is illegal, as in Brazil, intentionally induced clandestine abortions contributes to high numbers of maternal mortality. Around $5 \%$ of Brazilian women end up opting for the illegal use of misoprostol to terminate unwanted pregnancies (Vargas et al., 2000). This medical drug is a synthetic prostaglandin E1 analog, originally prescribed to treat gastric ulcers, which stimulate uterine contractions, leading to miscarriage. In Brazil, it has been banned from the market because of its use as an illegal abortion method (Costa, 1998; Schuler et al., 1999; da Silva Dal Pizzol et al., 2006; Allen and O'Brien, 2009). Misoprostol alone does not present great efficiency in inducing abortions, and can induce fetal abnormalities, especially if used in the first trimester of pregnancy (Gonzalez et al., 1998; Costa, 1998; da Silva Dal Pizzol et al., 2006; Allen and O'Brien, 2009). Furthermore, the increased use of drugs or herbs with perceived abortive actions by the population highlights the lack of control in selling and using prescription medications.

A cohort study of pregnant women treated in prenatal services in six Brazilian capitals revealed that 707 women used products to induce menstruation, which includes her- 
bal teas (34.4\%), sex hormones (28.3\%), and misoprostol (17\%) (Pizzol et al., 2008). The congenital anomaly risk was 2.74 times greater for fetuses exposed to misoprostol when compared to unexposed fetuses. Misoprostol is associated mainly to congenital paralysis of the $6^{\text {th }}$ and $7^{\text {th }}$ cranial nerves and to limb reduction defects due to fetal vascular disruption (Gonzalez et al., 1998; Vargas et al., 2000).

\section{Thalidomide}

Even after the immense international repercussion of the teratogenic potential effects of thalidomide, many cases of newborn malformation involving this medicine were registered in Brazil in different years. Thalidomide is a drug indicated for the treatment of erythema nodosum leprosum (ENL), and more recently, to a number of different medical conditions, due to its immunomodulatory properties (Vianna et al., 2011, 2015; Kim and Scialli, 2011;). The LatinAmerican Collaborative Study of Congenital Malformations (ECLAMC) reported 34 thalidomide embryopathy cases in South America from the 1960s to 1990s, of which 33 where in Brazil. Most of these cases involved mothers treated for leprosy, whose babies presented birth defects, such as phocomelia, hypoplastic glenoid, absence of thumbs, absence or hypoplasia of radius, a third arm bone, and polydactyly (Castilla et al., 1996).

Three cases were reported from 2005 to 2010 . From those, four involved mothers that underwent treatment for ENL and were unaware of pregnancy, while the third case involved self-medication of a pregnant woman who took thalidomide prescribed for her mother, who was being treated for multiple myeloma (Schuler-Faccini et al., 2007). The majority of cases involves lack of medical information, which is related to public health.

Despite safety concerns, the Brazilian population has a high consumption of thalidomide. The state of São Paulo leads the thalidomide drug distribution rates $(5,889,210$ thalidomide tablets), followed by Minas Gerais and Rio de Janeiro, from 2005 to 2010. In this period, there were 2,802 reported cases of limb reduction defects, with 192 cases compatible with a thalidomide embryopathy phenotype (TEP) (Vianna et al., 2015). This demonstrates the seriousness of this public health issue.

\section{Alcohol}

In 2012, alcohol was responsible for almost 3.3 million of deaths, corresponding to $5.9 \%$ of the total number of deaths worldwide. Excessive alcohol consumption prevails among adults aged 20-39 years, although alcohol use by young people starts at early ages - even from 12.5 years old (Vieira et al., 2007; World Health Organization, 2015b). Alcohol abuse during pregnancy can lead to Neonatal Abstinence Syndrome in babies. Alcohol is the teratogenic agent responsible for the Fetal Alcohol Syndrome (FAS), as well as Fetal Alcohol Spectrum Disorders (FASD), be- ing a major non-genetic cause of intellectual disability and behavioral problems (Abel and Sokol, 1987; Momino et al., 2012; Chapman and Wu, 2013; O'Leary et al., 2013).

In 2015 a study was carried out in a Brazilian orphanage in Recife to investigate the frequency of FASD. Children were evaluated by a multidisciplinary team, and the following results were obtained: $50 \%$ of the childrens mothers were reported as known alcohol abusers. Of these children, $18 \%$ presented general developmental delay, $3 \%$ had intellectual disabilities, $27 \%$ had cognitive impairment, $14 \%$ had attention deficit/hyperactivity, and 3\% presented autism. A total of $17 \%$ presented FASD, three children presented FAS, six presented partial FAS, and seven presented neurological disorder related to alcohol. About $16 \%$ of these children presented ocular changes, such as low vision, strabism and morphological changes of optic nerves, which shows the devastating effects of drug abuse during pregnancy. (Strömland et al., 2014)

\section{Illicit drugs}

Illicit drug consumption during pregnancy is another public health problem involving a potential embryo-fetal effect. The effects of these substances include low birth weight, intrauterine growth restriction and placental abruption, as well as premature birth or spontaneous abortion (Holbrook and Rayburn, 2014). Cocaine and its derivatives, such as crack and heroin, may have harmful effects on pregnancy (Cherukuri et al., 1988; Rizk et al., 1996; Costa et al., 2012). The extent of the problem can be estimated by the increase in the demand of medical care and costs with hospitalization and specialized treatment for drug-addicted pregnant women, as well as the increase in the number of premature births. Another issue is the increased rate of sexually transmitted diseases or other maternal infections related to illicit drug and alcohol use (Tüzün et al., 1999; Hwang et al., 2000), which can also be teratogenic, like syphilis.

\section{Concluding remarks}

This review presented fundamental aspects of teratogenic agents, bringing an overview about the number of cases of congenital anomalies, and their contribution to an increase in mortality rates, hospitalizations and treatments expenses for the Brazilian Unified Health System. We also present cases of congenital malformations involving teratogens, as well as the definitive classification of Zika virus infection as a teratogen and now a real public health problem.

Congenital anomalies caused by teratogenic agents are essentially avoidable, with a great impact on public health, on the economic and on social aspects. Public policies to prevent, care for, and treat these disabilities are extremely important to manage this public health issue. To address these problems, a collaborative agreement among the United Nations (UN), the WHO, the United Nations Children's Fund (UNICEF) and government leaders in 
2010 planned a series of low-cost and high-impact interventions to improve neonatal and infant health quality (World Health Organization, 2015a). The lack of public health structure in developing countries, however, still causes problems, reducing the viability of the proposal. Congenital abnormalities and neglected diseases are somewhat comparable, as both problems do not receive the necessary attention and prevail in developing regions. In Brazil, income transfers helped millions of people out of extreme poverty, but are still far from solving public health problems in the country. An intervention is needed, especially in the peripheral regions, with the application of preventive policies (Di Renzo et al., 2015). These policies may differ according to the countries' characteristics, but they should by all means emphasize health education of professionals, and the public,investment in primary reproductive healthcare, pregnancy planning, basic sanitation, and reliable registries with epidemiological data on congenital anomalies.

\section{Acknowledgments}

The authors would like to thank the funding agencies FAPESP (Grant Nr. 2011/13997-8), CNPq (Grants Nr. 311323/2011-1, Nr. 131306/2013-8 and 205453/2014-7) and CAPES for scholarships and financial support.

\section{References}

Abel E and Sokol R (1987) Incidence of fetal alcohol sydrome and economic impact of fas-related anamalies. Drug Alcohol Depend 19:51-70.

Alcantara D and O'Driscoll M (2014) Congenital microcephaly. Am J Med Genet Part C Semin Med Genet 166:124-139.

Allen R and O'Brien BM (2009) Uses of misoprostol in obstetrics and gynecology. Rev Obstet Gynecol 2:159-168.

Alván G, Danielsson BR, Kihlström I, Lundborg P, Prame B, Ridley E and Sannerstedt R (1995) Classification of drugs for teratogenic risk. Eur J Clin Pharmacol 48:177-178.

Ashwal S, Michelson D, Plawner L and Dobyns WB (2009) Practice parameter: Evaluation of the child with microcephaly (an evidence-based review): Report of the Quality Standards Subcommittee of the American Academy of Neurology and the Practice Committee of the Child Neurology Society. Neurology 73:887-897.

Atkinson B, Hearn P, Afrough B, Lumley S, Carter D, Aarons EJ, Simpson AJ, Brooks TJ and Hewson R (2016) Detection of Zika Virus in semen. Emerg Infect Dis 22:160-107.

Barrow MV (1971) A brief history of teratology to the early 20th century. Teratology 4:119-129.

Brasil P, Pereira Jr JP, Raja Gabaglia C, Damasceno L, Wakimoto M, Ribeiro Nogueira RM, Carvalho de Sequeira P, Machado Siqueira A, Abreu de Carvalho LM, Cotrim da Cunha D, et al. (2016) Zika virus infection in pregnant women in Rio de Janeiro - Preliminary report. N Engl J Med 375:2321-2334.

Brent RL (2001) The cause and prevention of human birth defects: What have we learned in the past 50 years? Congenit Anom (Kyoto) 41:3-21.
Bronberg R, Schuler-Faccini L, Ramallo V, Alfaro E and Dipierri J (2014) Spatial and temporal analysis of infant mortality from congenital malformations in Brazil (1996-2010). J Community Genet 5:269-282.

Calvet G, Aguiarv RS, Melo AS, Sampaio SA, de Filippis I, Fabri A, Araujo ES, de Sequeira PC, de Mendonça MCL, de Oliveira L, et al. (2016) Detection and sequencing of Zika virus from amniotic fluid of fetuses with microcephaly in Brazil: A case study. Lancet Infect Dis 16:653-660.

Campos GS, Bandeira AC and Sardi SI (2015) Zika virus outbreak, Bahia, Brazil. Emerg Infect Dis 21:1885-1886.

Cassina M, Salviati L, Di Gianantonio E and Clementi M (2012) Genetic susceptibility to teratogens: State of the art. Reprod Toxicol 34:186-191.

Castilla E, Ashton-Prolla P, Barreda-Mejia E, Brunoni D, Cavalcanti D, Correa-Neto J, Delgadillo J, Dutra M, Felix T, Giraldo A, et al. (1996) Thalidomide, a current teratogen in South America. Teratology 54:273-277.

Chapman SLC and Wu Li-Tzy (2013) Substance abuse among individuals with intellectual disabilities. Res Dev Disabil 33:1147-1156.

Charlton-Menys V and Durrington PN (2008) Human cholesterol metabolism and therapeutic molecules. Exp Physiol 93:2742.

Cherukuri R, Minkoff H, Feldman J, Parekh A and Glass L (1988) A cohort study of alkaloidal cocaine (" crack") in prenancy. Obstet Gynecol 72:147-151.

Cohlan SQ (1963) Teratogenic agents and congenital malformations. J Pediatr 63:650-659.

Conklin KA (2004) Chemotherapy-associated oxidative stress: Impact on chemotherapeutic effectiveness. Integr Cancer Ther 3:294-300.

Costa FS, Silva JJ da, Souza CM de and Mendes J (2008) Dinâmica populacional de Aedes aegypti (L) em área urbana de alta incidência de dengue. Rev Soc Bras Med Trop 41:309312.

Costa GM, Soibelman M, Zanchet DL, Costa PDM, Alberto C and Salgado I (2012) Pregnant crack addicts in a psychiatric unit. J Bras Psiquiatr 61:8-12.

Costa SH (1998) Commercial availability of misoprostol and induced abortion in Brazil. Int J Gynaecol Obstet 63(Suppl 1):S131-S139.

Cugola FR, Fernandes IR, Russo FB, Freitas BC, Dias JLM, Guimarães KP, Benazzato C, Almeida N, Pignatari GC, Romero S, et al. (2016) The Brazilian Zika virus strain causes birth defects in experimental models. Nature 534:267-271.

D'Ortenzio E, Matheron S, Lamballerie X de, Hubert B, Piorkowski G, Maquart M, Descamps D, Damond F, Yazdanpanah Y and Leparc-Goffart I (2016) Evidence of sexual transmission of Zika virus. N Engl J Med 374:2195-2198.

da Silva Dal Pizzol T, Knop FP and Mengue SS (2006) Prenatal exposure to misoprostol and congenital anomalies: Systematic review and meta-analysis. Reprod Toxicol 22:666-671.

De Moura LNB and Gomes KRO (2014) Planejamento familiar: Uso dos serviços de saúde por jovens com experiência de gravidez. Cienc Saude Colet 19:853-863.

Di Renzo GC, Conry JA, Blake J, DeFrancesco MS, DeNicola N, Martin JN, McCue KA, Richmond D, Shah A, Sutton P, et al. (2015) International Federation of Gynecology and Obstetrics opinion on reproductive health impacts of exposure 
to toxic environmental chemicals. Int J Gynecol Obstet. 131:219-225.

Edison RJ and Muenke M (2004) Central nervous system and limb anomalies in case reports of first-trimester statin exposure. N Engl J Med 350:1579-1582.

Egbe A, Uppu S, Lee S, Stroustrup A, Ho D and Srivastava S (2015) Congenital malformations in the newborn population: A population study and analysis of the effect of sex and prematurity. Pediatr Neonatol 56:25-30.

Finnell RH (1999) Teratology: General considerations and principles. J Allergy Clin Immunol 103:337-342.

Food and Drug Administration (2014a) Content and format of labeling for human prescription drug and biological products requirements for pregnancy and lactation labeling. Dep Health Hum Serv Food Federal Regist 79:1-144.

França GV, Schuler-Faccini L, Oliveira WK, Henriques CMP, Carmo EH, Pedi VD, Nunes ML, Castro MC, Serruya S, Silveira MF, et al. (2016) Congenital Zika virus syndrome in Brazil: A case series of the fi rst 1501 livebirths with complete investigation. Lancet 388:891-897.

Garcez PP, Loiola EC, Costa RM da, Higa LM, Trindade P, Delvecchio R, Nascimento JM, Brindeiro R, Tanuri A and Rehen SK (2016) Zika virus impairs growth in human neurospheres and brain organoids. Science 352:816-818.

Garcias GDL and Schüler-Faccini L (2004) The beliefs of mothers in southern Brazil regarding risk-factors associated with congenital abnormalities. Genet Mol Biol 27:147-153.

Giavini E and Menegola E (2012) Biomarkers of teratogenesis: Suggestions from animal studies. Reprod Toxicol 34:180185

Gilbert-Barness E (2010) Teratogenic causes of malformations. Ann Clin Lab Sci 40:99-114.

Gonzalez CH, Marques-Dias MJ, Kim CA, Sugayama SM, Da Paz JA, Huson SM and Holmes LB (1998) Congenital abnormalities in Brazilian children associated with misoprostol misuse in first trimester of pregnancy. Lancet 351:16241627.

Hale F (1933) Pigs born without eye balls. J Hered 24:105-110.

Hansen JM (2006) Oxidative stress as a mechanism of teratogenesis. Birth Defects Res C Embryo Today 78:293-307.

Holbrook BD and Rayburn WF (2014) Teratogenic risks from exposure to illicit drugs. Obstet Gynecol Clin North Am 41:229-239.

Holmes LB (2002) Teratogen-induced limb defects. Am J Med Genet 112:297-303.

Horovitz DDG, Llerena Jr JC and Mattos RA (2005) Atenção aos defeitos congênitos no Brasil: Panorama atual. Cad Saúde Pública 21:1055-1064.

Hwang LY, Ross MW, Zack C, Bull L, Rickman K and Holleman M (2000) Prevalence of sexually transmitted infections and associated risk factors among populations of drug abusers. Clin Infect Dis 31:920-926.

Johansson MA, Mier-y-Teran-Romero L, Reefhuis J, Gilboa SM and Hills SL (2016) Zika and the risk of microcephaly. N Engl J Med 375:1-4.

Kalter H (2003) Teratology in the 20th century: Environmental causes of congenital malformations in humans and how they were established. Neurotoxicol Teratol 25:131-282.

Kim JH and Scialli AR (2011) Thalidomide: The tragedy of birth defects and the effective treatment of disease. Toxicol Sci 122:1-6.
McMichael C, Waters E and Volmink J (2005) Evidence-based public health: What does it offer developing countries? J Public Health (Oxf) 27:215-221.

Menegola E, Di Renzo F, Broccia ML, Prudenziati M, Minucci S, Massa V and Giavini E (2005) Inhibition of histone deacetylase activity on specific embryonic tissues as a new mechanism for teratogenicity. Birth Defects Res Part B Dev Reprod Toxicol 74:392-398.

Mlakar J, Korva M, Tul N, Popovic M, Poljak-Prijatelj M, Mraz J, Kolenc M, Resman RK, Vesnaver VT, Voduek VF, et al. (2016) Zika virus associated with microcephaly. N Engl J Med 374:951-958.

Momino W, Félix TM, Abeche AM, Zandoná DI, Scheibler GG, Chambers C, Jones KL, Flores RZ and Schüler-Faccini L (2012) Maternal drinking behavior and Fetal Alcohol Spectrum disorders in adolescents with criminal behavior in southern Brazil. Genet Mol Biol 35:960-965.

Musso D, Roche C, Robin E, Nhan T, Teissier A and CaoLormeau VM (2015) Potential sexual transmission of zika virus. Emerg Infect Dis 21:359-361.

Niakan KK, Han J, Pedersen RA, Simon C and Pera RAR (2012) Human pre-implantation embryo development. Development 139:829-841.

Nutbeam DON (2006) Health literacy as a public health goal: A challenge for contemporary health education and communication strategies into the 21 st century. Health Promot Int $15: 259-268$

O'Leary C, Leonard H, Bourke J, D'Antoine H, Bartu A and Bower C (2013) Intellectual disability: Population-based estimates of the proportion attributable to maternal alcohol use disorder during pregnancy. Dev Med Child Neurol 55:271277.

Parker SE, Mai CT, Canfield MA, Rickard R, Wang Y, Meyer RE, Anderson P, Mason CA, Collins JS, Kirby RS, et al. (2010) Updated national birth prevalence estimates for selected birth defects in the United States, 2004 - 2006. Birth Defects Res (Part A) 88:1008-1016.

Passos-Bueno MR, Bertola D, Horovitz DDG, de Faria Ferraz VE and Brito LA (2014) Genetics and genomics in Brazil: A promising future. Mol Genet Genomic Med 2:280-291.

Petrini J, Damus K, Russell R, Poschman K, Davidoff MJ and Mattison D (2002) Contribution of birth defects to infant mortality in the United States. Teratology 66(Suppl 1):S3-S6.

Pizzol T da SD, Sanseverino MTV and Mengue SS (2008) Exposure to misoprostol and hormones during pregnancy and risk of congenital anomalies. Cad Saude Publica 24:1447-1453.

Raman-Wilms L, Tseng A, Wighardt S, Einarson T and Koren G (1995) Fetal genital effects of first-trimester sex hormone exposure: A meta-analysis. Obstet Gynecol 85:141-149.

Rasmussen SA, Jamieson DJ, Honein MA and Petersen LR (2016) Zika virus and birth defects - Reviewing the evidence for causality. N Engl J Med 374:1981-1987.

Reidpath DD and Allotey P (2003) Infant mortality rate as an indicator of population health. J Epidemiol Community Health 57:344-346

Rizk B, Atterbury JL and Groome LJ (1996) Reproductive risks of cocaine. Hum Reprod Update 2:43-55.

Scholl TO and Johnson WG (2000) Folic acid: Influence on the outcome of pregnancy. Am J Clin Nutr 71:1295S-303S. 
Schüler L, Pastuszak A, Sanseverino TV, Orioli IM, Brunoni D, Ashton-Prolla P, Silva da Costa F, Giugliani R, Couto AM, Brandao SB, et al. (1999) Pregnancy outcome after exposure to misoprostol in Brazil: A prospective, controlled study. Reprod Toxicol 13:147-151.

Schuler-Faccini L, Soares RCF, de Sousa ACM, Maximino C, Luna E, Schwartz IVD, Waldman C and Castilla EE (2007) New cases of thalidomide embryopathy in Brazil. Birth Defects Res A Clin Mol Teratol 79:671-672.

Shepard TH (1982) Detection of human teratogenic agents. J Pediatr 101:810-815.

Shepard TH (1979) Teratogenicity of therapeutic agents. Curr Probl Pediatr 10:1-42.

Shepard TH (1994) "Proof" of human teratogenicity. Teratology 50:97-98.

Strömland K, Ventura LO, Mirzaei L, Fontes de Oliveira K, Marcelino Bandim J, Parente Ivo A and Brandt C (2014) Fetal alcohol spectrum disorders among children in a Brazilian orphanage. Birth Defects Res A Clin Mol Teratol 103:178185.

Tüzün B, Tüzün Y and Wolf R (1999) Alcohol intake and sexually transmitted diseases. Clin Dermatol 17:469-478.

van Gelder MMHJ, van Rooij IALM, Miller RK, Zielhuis GA, de Jong-van den Berg LTW and Roeleveld N (2010) Teratogenic mechanisms of medical drugs. Hum Reprod Update 16:378-94.

Vargas FR, Schuler-Faccini L, Brunoni D, Kim C, Meloni VF, Sugayama SM, Albano L, Llerena Jr JC, Almeida JC, Duarte A, et al. (2000) Prenatal exposure to misoprostol and vascular disruption defects: A case-control study. Am J Med Genet 95:302-306.

Vianna FSL, Lopez-Camelo JS, Leite JCL, Sanseverino MTV, Dutra MDG, Castilla EE and Schüler-Faccini L (2011) Epidemiological surveillance of birth defects compatible with thalidomide embryopathy in Brazil. PLoS One 6:e21735.

Vianna FSL, Oliveira MZ, Sanseverino MTV, Morelo EF, Rabello Neto D de L, Lopez-Camelo J, Camey SA and SchulerFaccini L (2015) Pharmacoepidemiology and thalidomide embryopathy surveillance in Brazil. Reprod Toxicol 53:6367.

Vieira DL, Ribeiro M, Romano M and Laranjeira RR (2007) Alcohol and adolescents: Study to implement municipal policies. Rev Saude Publica 41:1-8.

Watemberg N, Silver S, Harel S and Lerman-Sagie T (2002) Significance of microcephaly among children with developmental disabilities. J Child Neurol 17:117-122.

Waterham HR (2006) Defects of cholesterol biosynthesis. FEBS Lett 580:5442-5449.

Wells PG, Kim PM, Laposa RR, Nicol CJ, Parman T and Winn LM (1997) Oxidative damage in chemical teratogenesis. Mutat Res 396:65-78.

Wilson JG (1977) Current status of teratology: General principles and mechanisms derived from animal studies. In: JG Wilson \& FC Fraser (eds) Handbook of Teratology. Plenum Press, New York, 488 pp.
Winn L and Wells P (1995) Free radical-mediated mechanisms of anti-convulsant teratogenicity. Eur J Neurol 2:5-29.

Xu J, Murphy S, Kochanek K and Bastian B (2016) Deaths: Final data for 2013. National vital statistics reports. Natl Cent Heal Stat 64:1-117.

\section{Internet resources}

Brazil Ministry of Health (2015) Microcephaly- epidemiological bulletin. http://portalsaude.saude.gov.br/images/pdf/2015/novembro/30/Microcefalia-2-boletim.pdf, accessed June 22, 2016.

Brazil Ministry of Health (2016) Microcephaly- epidemiological bulletin. http://portalsaude.saude.gov.br/in-

dex.php/cidadao/princi-

pal/agencia-saude/24202-ministerio-da-saude-confirma-1616-casos-de-microcefalia-em-todo-o-pais, accessed June 22, 2016.

Food and Drug Administration (2014b) Code of Federal Regulations Title 21. (21CFR201.57). Avalilable:

http://www.accessdata.fda.gov/scripts/cdrh/cfdocs/cfCFR/ CFRSearch.cfm?fr = 201.57, accessed June 2, 2014.

World Health Organization (2015a) Congenital anomalies. Fact sheet No370.

http://www.who.int/mediacentre/factsheets/fs370/en/, accessed November 23, 2015.

World Health Organization (2015b) Alcohol. Fact sheet N³49. http://www.who.int/mediacentre/factsheets/fs349/en/, accessed November 23, 2015.

World Health Organization (2016) WHO statement on the first meeting of the International Health Regulations (2005) (IHR 2005) Emergency Committee on Zika virus and observed increase in neurological disorders and neonatal malformations. http://www.who.int/mediacentre/news/statements/2016/1st-emergency-committee-zika/en/, accessed February 25, 2016.

\section{Supplementary Material}

The following online material is available for this article: Table S1 - Main teratogen categories and respective embryo-fetal effects during pregnancy.

Table S2 - Cases involving congenital anomalies from 2008 to 2013.

Table S3 - Fetal deaths involving congenital anomalies from 2008 to 2013.

Table S4 - Infant hospitalizations involving congenital anomalies from 2008 to 2013.

Table S5 - Number of deaths of infant hospitalized involving congenital anomalies from 2008 to 2013.

Table S6 - Average cost in US dollars of hospitalizations involving congenital anomalies from 2008 to 2013

Associate Editor: Carlos F.M. Menck

License information: This is an open-access article distributed under the terms of the Creative Commons Attribution License (type CC-BY), which permits unrestricted use, distribution and reproduction in any medium, provided the original article is properly cited. 